\title{
Distribution of Important and Word-Cued Autobiographical Memories in 20-, 35-, and 70-Year-Old Adults
}

\author{
David C. Rubin and Matthew D. Schulkind \\ Duke University
}

\begin{abstract}
For word-cued autobiographical memories, older adults had an increase, or bump, from the ages 10 to 30. All age groups had fewer memories from childhood than from other years and a powerfunction retention function for memories from the most recent 10 years. There were no consistent differences in reaction times and rating scale responses across decades. Concrete words cued older memories, but no property of the cues predicted which memories would come from the bump. The 5 most important memories given by 20 - and 35 -year-old participants were distributed similarly to their word-cued memories, but those given by 70 -year-old participants came mostly from the single 20 -to-30 decade. No theory fully accounts for the bump.
\end{abstract}

Galton (1879) found that he could cue memories from his life by using objects in the environment. He then moved into the laboratory, used lists of words as cues, recorded his reaction times to produce memories, and noted the distribution of memories across the life span. Crovitz and Schiffman (1974) revived this technique by providing participants with word cues and requesting personal, episodic, autobiographical memories. As used here, autobiographical memory is cpisodic memory (Tulving, 1972), though it differs in the tasks used to measure it and its emphasis on a sense of reliving the past (Brewer, 1996). The English verb recollect offers a more precise description of the phenomenon than the verb remember (Baddeley, 1992; Brewer, 1996). In this form, autobiographical or recollective memory has become an active topic in cognitive psychology (for reviews, see Brewer, 1996; Conway, 1990; Conway \& Rubin, 1993; Conway, Rubin, Spinnler, \& Wagenaar, 1992; Neisser \& Fivush, 1994; Rubin, 1986, 1996).

We add to what is known about the distribution of autobiographical memories across the life span by using standard techniques and methods from cognitive psychology. We ignore the issue of the accuracy of such memories both because it is an especially thorny one (Robinson, 1996) and because we make little of the contents of the memories themselves. Rather we analyze the memories mainly in terms of the date attributed to each. Although systematic errors in dating occur because of boundary effects and the cyclical nature of our definition of time, for sludies of autobiographical memory that are not restricted to

David C. Rubin and Matthew D. Schulkind, Department of Experimental Psychology, Duke University.

Support was provided by National Institute of Aging Grant AG04278 and the Duke University Arts and Science Research Council.

We thank Kevin Mallory for testing the participants and performing the initial data reduction and Herb Crovitz, Joe Fitzgerald, and Tamara Rahhal for comments on a version of this article.

Correspondence concerning this article should be addressed to David C. Rubin, Department of Experimental Psychology, Duke University, Durham, North Carolina 27708-0086. Electronic mail may be sent via Internet to rubin@psych.duke.edu. a bounded time period, the reported dates are unbiased estimates of the actual dates (Huttenlocher, Hedges, \& Prohaska, 1988; Larsen, Thompson, \& Hansen, 1996; Rubin \& Baddeley, 1989).

The main issue to be addressed here is that of the distribution of autobiographical memories across the adult life span. In past research with older adults, similar distributions have been obtained repeatedly (Holding, Noonan, Pfau, \& Holding, 1986; Hyland \& Ackerman, 1988; Rubin \& Schulkind, in press; Rubin, Wetzler, \& Nebes, 1986). They are of interest here because they can be analyzed in terms of three theoretically and empirically separate components, one of which still lacks a clear explanation in terms of cognitive constructs.

The first component is a retention function described mathematically by the power function $y=a \cdot \mathrm{t}^{-b}$ or $\ln (y)=-b \cdot \ln (t)$ $+\ln (a)$. This monotonically decreasing function drops rapidly at first and then more slowly so that equal ratios of time cause equal ratios in amount recalled. For college students and for the most recent 10 or 20 years of older participants' lives, this function by itself provides an extremely good fit with correlations in the .98 range (Rubin, 1982). The same function also provides one of the best fits to laboratory retention studies (Anderson \& Schooler, 1991; Rubin \& Wenzel, 1996; Wickelgren, 1975; Wixted \& Ebbesen, 1991). Although Rubin and Wenzel found some differences in fit between laboratory and autobiographical memory retention functions, the power function can describe retention from both kinds of episodic memory studies.

The basic finding is extremely reliable in spite of the lack of controls placed on the participants. Not only do different laboratories produce the same power-function retention function for the most recent decades of life, but also the power function exists even when individual participants or responses to individual words are analyzed (Rubin, 1982; Rubin \& Schulkind, in press), when visual or olfactory instead of verbal cues are given (Rubin, Groth, \& Goldsmith, 1984), and even when the participants produce responses in the absence of any cue words ( $\mathrm{Ru}-$ bin, 1982). This holds for the most recent 10 to 20 years of recall of junior high school students, college students, middle aged, and older participants (Fitzgerald \& Lawrence, 1984; Rubin et al.'s, 1986, reanalysis of Franklin \& Holding, 1977; Ru- 
bin \& Schulkind, in press ). Moreover, the slopes of the power function do not vary with age, implying that the retrieval of autobiographical memories is similar for the most recent 20 years of adult participants' lives independent of their age. This is consistent with the laboratory literature that shows that older adults do not have any large or consistent deficits in retention (Giambra \& Arenberg, 1993; Rubin \& Wenzel, 1996; Rubin et al., 1986; Salthouse, 1991; Wickelgren, 1975). That is, in laboratory tasks, as in the autobiographical memory tasks, the rate of forgetting of older and younger adults appears to be the same (or at least very similar), assuming the initial level of encoding is the same.

A second component of the distribution of autobiographical memories is a reduction in the memories coming from the earliest years of participants' lives: an early childhood memory or childhood amnesia function. Much work and much more speculation have surrounded this function, so its boundaries are relatively well-known. Here childhood amnesia is a mathematical necessity needed to force the function describing the distribution to go to zero at birth. Retention is a function of $t$, which is time measured from an event (i.e., time, $t$, is measured in hours ago). In contrast, childhood amnesia is a function of age or time measured from birth. If people of different ages are tested, it is difficult to fit the data without both a retention component based on $t$ and a childhood amnesia component based on age at the time of the memory (i.e., current age $-t$ ).

The third component could be termed reminiscence. However, because all we imply by this component is that more autobiographical memories are recalled from when a person is between 10 - and 30-years-old (henceforth 10 -to-30 period) than would be expected from the other two components, we use the theoretically more neutral term bump. We leave the theoretically richer term reminiscence to refer to conscious recollections seemingly done for their own purposes rather than those requested by another or used for the retrieval of specific information. (For attempts to integrate these two terms see Fitzgerald, 1996, and Webster and Cappeliez, 1993.) Additionally, people with many forms of amnesia often have better memory for older than for more recent events. There is currently not a good measure of the extent to which this is present in people without amnesia. Providing quantitative underpinnings for this phenomenon and for reminiscence is one goal of this research.

The definition of the bump used here was derived from empirical studies of autobiographical memory in which the cue word technique was used. In such studies, there is a nonmonotonic distribution with an increase in the number of memories from between the ages of 10 and 30 (e.g., Rubin et al.'s, 1986, reanalysis of data from Fitzgerald \& Lawrence, 1984, and Franklin \& Holding, 1977, as well as Hyland \& Ackerman, 1988; and Jansari \& Parkin, 1996). The only way not to get this result seems to be to ask adults to recall events from individual thirds, quarters, or fifths of their life span for 5 or 10 minutes (Howes \& Katz, 1992; Rabbitt \& Winthorpe, 1988). It appears that individuals have more memories from any fifth of their life than they can report in 10 minutes (Crovitz, Schiffman, \& Apter, 1991).

The bump has also been observed in studies that do not use cue words but rather ask for either a small number of important or vivid memories or a longer narrative containing such memories. Using these techniques, several researchers found an in- crease in vivid and important autobiographical memories within the 10-to-30 period. For instance, instead of cuing each memory with a single word as in the studies just reviewed, Fromholt and Larsen's (1991, 1992; Fromholt, Larsen, \& Larsen, 1995) participants were asked to spend $15 \mathrm{~min}$ recalling events that had been important in their lives. Other researchers have asked for vivid memories (Benson et al., 1992; Cohen \& Faulkner, 1988; Fitzgerald, 1988), and Fitzgerald (1996) asked adults for memories that would go into a book about their lives. In all studies there was an increase in memories somewhere in the 0- to 30 -year-old range. Fitzgerald suggested that the vivid memories given are part of a life narrative (Gergen \& Gergen, 1983) and their increased frequency is at a time when identity is being formed, though not all vivid memories need be of this kind (Neisser, 1988). If the bump is a result of memories from 10 to 30 being a central part of a narrative, then memories from the bump should appear more often to requests for vivid or important memories, as they did in the studies just cited. In addition, word-cued memories from the bump might be judged to be more important, more significant, and more often told.

With these studies as an empirical base, we designed an experiment to quantify the basic findings outlined as precisely as possible and to understand the distribution and recall of autobiographical memories in terms of the standard methods and theories of cognitive psychology. In addition to the distribution of memories across the life span, we recorded participants' reaction times to produce a memory and asked them to rate their memories on a number of qualitative scales. Following a long tradition in cognitive psychology, we examined the properties of the word cues to see if they have an effect on the other variables. To try to clarify the relation between autobiographical memories cued by words and autobiographical memories judged to be the most important, we asked the same participants to provide both. We choose to ask about important memories (as opposed to the vivid memories used by many researchers) to focus on the narrative theory and not to focus on the sensory aspects of the memories.

In a sense, our study is descriptive in that we quantified the phenomenon more fully. In this spirit, throughout the article we set our $p$ level at .05 and only mention statistical significance when results fail to be significant or produce marginal effects that others might want to reinterpret or when summarizing sets of analyses that are not fully reported. However, we also designed our collection of age groups, tasks, and dependent measures to allow us to test several hypotheses about the bump.

The first hypothesis is that the bump in the cue word method is caused by demand characteristics. The cue word procedure is among the most open ended in cognitive psychology, and so the participant's conception of the experimental task is not clear The method produces robust, reliable findings, but there are minor differences in distributions that have no clear cause. Thus, for instance, Jansari and Parkin's (1996) results have more early memories than other studies. To pursue this issue, a modification, or bias, in the standard instructions was made and tested in the current experiment. Instead of asking for events in a memory experiment, we asked for memories in an autobiographical memory experiment, and we changed our one example to be of a childhood memory instead of a recent one. This manipulation was intended to favor earlier memories, and it might focus 
attention on the 10-to-30 period in which people might look for more prototypical autobiographical memories. In this way, we hoped to begin to explore the limits of the phenomenon and its stability under experimental manipulation. If the bump is due to a selective search caused by demand characteristics, then changes in demand characteristics should have a large effect on the bump.

The second hypothesis is related to, but different from, the first. Bump memories may be more frequent because people are willing to spend more time looking for them. That is, people may focus on this period and be slower to terminate a search for memories from it. Under this hypothesis, the bump is a speed-availability analog of the standard speed-accuracy trade-off; if the participants are slower to terminate searches for memories in the bump, more memories will be found in the bump than in other periods, assuming that the underlying distribution of memories available for recall within any given search time is the same. Evidence for the second hypothesis would be slower mean reaction times in the 10 -to-30 period.

The third hypothesis is that there are more memories from the 10-to-30 period that are judged by the participants themselves to be especially important and therefore more worthy of reporting and that these memories are the basis for the increased number of memories in the bump. To test this we took two approaches. The first was to ask participants for the five most important events in their lives as well as for the more neutral word-cued memories. If these important memories are the scaffolding on which the bump is built, they should have a distribution similar to the bump. The second approach was to ask for ratings of the significance of a sample of memories that is evenly distributed across the life span and to see if those in the 10-to-30 period are rated more highly.

A fourth hypothesis is related to but can be separated from the important event hypothesis. The bump may be due to more events from the 10-to-30 period being included in one's central life narrative (Fitzgerald, 1988, 1996). Under this hypothesis, such events would be judged to be important or significant and would come from the same period as a participant's five most important events, but such events would also be told more. We therefore included a question on frequency of rehearsal.

A fifth hypothesis can be made for novelty rather than importance. There are more first occurrences (Robinson, 1992) and other novel events in the bump. Such novel events suffer less from proactive interference and benefit from more attention or more effort after meaning as the novel event is being understood (Rubin, Rahhal, \& Poon, in press). In addition, first or unique events from specific life periods are produced more quickly (Jansari \& Parkin, 1996). A rating scale of novelty was therefore included for a sample of memories uniformly distributed across the life span. Similarly, according to a sixth hypothesis, vivid (Cohen, Conway, \& Maylor, 1994) or emotional memories occur more during the 10 -to-30 period, and such memories, as opposed to important and novel memories, cause the bump. To test this hypothesis, we included rating scales of vividness and pleasantness (from which emotionality is calculated). A second, more indirect way to examine the same hypothesis is to include words varying in imagery, concreteness, and emotionality and to measure whether words high on these scales will differentially cue memories from the bump.
The first six hypotheses are not mutually exclusive; the seventh hypothesis, as considered here, is. It is possible that people encode memories better during the 10 -to-30 period or encode them in a way that leads to better recall later in life for reasons not considered in the other hypotheses. Under this hypothesis, the bump memories are not more important, novel, vivid, or emotional nor do people put any special effort into recalling bump memories. Rather, more memories are recalled from the bump because more lasting memories are stored and maintained from the 10-to-30 period than from other periods of the life span for reasons not considered in the other hypotheses. Memories from the bump may be encoded or retained better because of differences in basic biological processes or because the environment in general, and not just the aspect of it that is going to be remembered, is rapidly changing for a person at this time but because no specific mechanism can be found, no test can be offered. For the seventh hypothesis to be considered from the evidence collected here, a bump would have to be observed in the absence of evidence for any of the first six hypotheses. Although such negative evidence is not the most convincing, it would be consistent with it and would lead one to look for other support for differential encoding (e.g., Rubin et al., in press).

\section{Method}

\section{Participants}

Six groups of 20 participants each took part. The groups were labeled by the age and condition of the participants as $20,20 \mathrm{~b}, 35,70,73$, and $73 \mathrm{~b}$, where $\mathrm{b}$ stands for biased instructions. The 20 -year-old participants were all Duke University undergraduates who received either credit toward their introductory psychology participation requirement or $\$ 5 / \mathrm{hr}$. The remaining participants were contacted through the Subject Register of the Center for the Study of Aging and Human Development at Duke University Medical Center. They received $\$ 10 /$ session. Participants in each group celebrated the birthday that is the label of their group between 1 and 11 months before testing. Thus, all the undergraduates in the 20 and $20 \mathrm{~b}$ groups were between 20 years 1 month and 20 years 11 months old. The 73 group was included as a replication of the 70 group and to provide enough participants in a narrow range of ages to match the $73 \mathrm{~b}$ group. The 35 group was included to examine individuals at a time near to the end of the bump period. Data for the distribution of memories over the life span and for reaction times from the 20 and 70 groups were reported in another paper (Rubin \& Schulkind, in press).

Before the experiment began, all participants answered questions and had their blood pressure taken. This background information is included in Table 1. The health rating question asked participants to compare their health with other people their own age on a scale of 1 (excellent), 2 (good), 3 (average), 4 (fair), to 5 (poor). The participants' ratings of whether their daily activities were in any way impaired because of their health were done on a scale of 1 (none), 2 (a little), 3 (some), 4 (a significant amount), to 5 ( $a$ lot $)$. Examination of Table 1 indicates that the participants were generally healthy, well educated, and, given their large age differences, well matched.

\section{Materials}

The 124 words used to cue autobiographical memories were taken from 125 words previously normed on 51 properties (Rubin, 1980). The word breast was eliminated from the original 125 words because of the likelihood of it producing a potentially embarrassing autobio- 
Table 1

Mean Values for Demographic Information

\begin{tabular}{|c|c|c|c|c|c|c|c|c|c|}
\hline \multirow[b]{2}{*}{ Group } & \multirow[b]{2}{*}{ Men } & \multirow{2}{*}{$\begin{array}{c}\text { Age } \\
\text { (in years) }\end{array}$} & \multicolumn{2}{|c|}{$\begin{array}{l}\text { Education } \\
\text { (in years) }\end{array}$} & \multicolumn{2}{|c|}{$\begin{array}{l}\text { Health } \\
\text { rating }\end{array}$} & \multicolumn{2}{|c|}{$\begin{array}{l}\text { Activity } \\
\text { rating }\end{array}$} & \multirow{2}{*}{$\begin{array}{c}\text { Blood } \\
\text { pressure }\end{array}$} \\
\hline & & & $M$ & $S D$ & $M$ & $S D$ & $M$ & $S D$ & \\
\hline 20 & 8 & 20.37 & 13.60 & 0.60 & 1.75 & 0.85 & 1.75 & 0.85 & $133 / 78$ \\
\hline $20 \mathrm{~b}$ & 9 & 20.33 & 13.40 & 0.50 & 2.15 & 0.67 & 1.10 & 0.31 & $116 / 68$ \\
\hline 35 & 8 & 35.54 & 17.90 & 1.60 & 1.65 & 0.75 & 1.20 & 0.70 & $112 / 69$ \\
\hline 70 & 7 & 70.34 & 15.70 & 2.90 & 1.95 & 1.05 & 1.25 & 0.72 & $106 / 68$ \\
\hline 73 & 13 & 73.56 & 17.00 & 3.70 & 1.75 & 0.85 & 1.45 & 0.60 & $140 / 79$ \\
\hline $73 b$ & 4 & 73.61 & 14.70 & 3.30 & 1.80 & 0.83 & 1.55 & 0.83 & $136 / 76$ \\
\hline
\end{tabular}

Note. Groups are labeled by their age; $\mathbf{b}$ indicates biased instructions.

graphical memory. The 124 cue words were presented in a different random order to each participant.

\section{Procedure}

The procedure followed earlier work in this area. The participants were tested individually. Each participant was asked to provide one event for each cue word. During the initial contact, participants in the standard $20,35,70$, and 73 groups were asked to take part in a memory experiment, whereas participants in the biased $20 \mathrm{~b}$ and $73 \mathrm{~b}$ groups were asked to take part in an autobiographical memory experiment. In the instructions for the biased groups, the word memory was substituted throughout for the word event. In the one example and in the one reference to the range of times in the life span, recent times were used for the standard group and remote times for the biased group. The following excerpt from the standard instructions contains the biased version changes in parentheses.

The event (memory) you think of does not have to be important; it does not have to be interesting; it can come from any point in time in your life, even as recently as this morning (even from as far back as you can remember). The event (memory) does need to be very specific, however. By that I mean that it must have happened at a very particular place and point in time. For example, if I were to use the word store, you might think of having gone to the hardware store yesterday (remember having gone to a little country store with your grandfather when you were five).

Participants worked at a desk facing a wall so that the experimenter was out of sight. Reaction times were recorded from the end of the reading of each word until writing began on a memory. The participants recorded a brief description of their memory. They were asked to try to make the descriptions generally clear and specific but were told to use initials or other symbols intelligible only to themselves whenever they wished. The participants were informed that they would return to the memories later to answer questions about them. After all 124 cue words had been presented, the participants were asked to return to each of their descriptions and date it with the month, day, and year it occurred. The participants were then asked to record in two to three sentences five of the most important events of their lives and to date those.

Either between the first and second session or while the participant was occupied with the five important event descriptions, depending on when the participant finished the previous step, the experimenter prepared a histogram of the dates of the 124 events broken down into 5 year blocks. From each block the experimenter randomly selected memories for more detailed investigation. For the 70,73 , and $73 \mathrm{~b}$ groups, 1 memory was selected per 5-year block; for the 35 group, 2 memories were selected per 5-year block; and for the 20 and $20 \mathrm{~b}$ groups, 3 memo- ries were selected per 5-year block. If there were not enough memories in any block, all memories in that block were used, but none outside of it were substituted. The goal was to have at least 1 memory from each block but also to have approximately the same number of memories from each person regardless of age. Thus, the 70- and 35-year-old participants could have a maximum of 14 memories selected, and the 20-yearold participants a maximum of 12 memories. The experimenter then recorded the serial order number of each selected memory, the order that they were produced by the participant, on a form for descriptions and rating scales so that the participant could refer back to the original sheets of short descriptions and dates.

When participants were finished with the descriptions of the five important events, they were asked for similar descriptions of the memories selected from the 124 cued events. After those descriptions were complete, participants were asked to answer a series of questions about each of the descriptions, both the five important ones and the experimenter-selected ones. Five 7-point rating scales were used to evaluate the following aspects of the events: vividness (no image to as clear an image as the original), pleasantness (equal to my most unpleasant memory to equal to my most pleasant memory), significance (made no difference in my life to changed my life as much as any event), novelty (totally routine to equal to my most unusual event), and frequency of rehearsal (never to as often as any event in my life). A 3-point scale was used for one question. It asked from what memory perspective (Nigro \& Neisser, 1983; Robinson \& Swanson, 1993) the event was visualized: +1 (field of view of the original participant as a perceiver), -1 (point of view of an observer), and 0 (neither perspective fit). One participant in the 73 group and 2 in the $73 b$ groups did not fill in the rating scales because of experimenter error. A two-line explanation of why the participant thought that event was remembered proved unscorable. An emotionality scale was calculated as the absolute value of the pleasantness scale value minus four (i.e., absolute distance from neutral).

The experiment took at least two sessions. The 20-year-old participants generally took about $1 \mathrm{hr}$ and $45 \mathrm{~min}$ for the first session and 1 hr and $20 \mathrm{~min}$ for the second session. The 35 -year-old participants generally took close to $2 \mathrm{hr}$ for the first session and $1 \mathrm{hr}$ and $45 \mathrm{~min}$ for the second session. The 70-year-old participants generally took $2 \mathrm{hr}$ each time, and some required a third session of up to $2 \mathrm{hr}$ to complete the experiment. The first session usually went as far as the dating of the 124 events. No participant was asked to go beyond providing the five most important events in the first session. All participants finished within a 1 -week period.

\section{Results}

Because we tested six groups and used many dependent measures, there are many results to analyze and report. Table 2 
Table 2

Total Number of Memories for Each Group for Various Periods

\begin{tabular}{lrrrrrrr}
\hline & & & & \multicolumn{2}{c}{ Before } & \\
\cline { 5 - 6 } Group & \multicolumn{1}{c}{$<$} & & $<1$ & $<10$ & & \\
\cline { 5 - 6 } & day & year & years & Age 10 & Age 3 & All \\
\hline 20 & 121 & 1,318 & 1,971 & 165 & 2 & 2,272 \\
$20 \mathrm{~b}$ & 78 & 721 & 1,850 & 361 & 6 & 2,330 \\
35 & 190 & 1,405 & 1,828 & 49 & 0 & 2,355 \\
70 & 231 & 989 & 1,300 & 93 & 3 & 2,313 \\
73 & 218 & 622 & 963 & 118 & 7 & 2,181 \\
$73 \mathrm{~b}$ & 51 & 517 & 830 & 238 & 8 & 2,007 \\
\hline
\end{tabular}

Note. All values are for the entire group of 20 individuals. The maximum number of possible memories is 2,480 ( 124 cues $\times 20$ participants). Groups are labeled by their age; $b$ indicates biased instructions.

provides the number of dated memories on which the various analyses are based. Initially, we present the distribution of wordcued memories, organizing these results into three sections: (a) memories from the most recent decade, (b) memories from the earliest decade of life, and (c) memories from the life span as a whole. For the undergraduates, the first two sections account for their entire 20 years of memories. Next, we attempt to further understand the memory retrieval process by using (a) the reaction times to produce cued memories, (b) the age of the memories and the reaction times as predicted by properties of the cue words, (c) the distribution of the five most important memories, and (d) the rating scale responses participants made to their important memories and to their word-cued memories. We note the effect of the bias instructions in each analysis.

\section{The Distribution of Word-Cued Memories Over the Most Recent Decade}

In examining the retention of memories over the most recent 10 years, we used logarithmic scales because in past work ( $\mathrm{Ru}$ bin, 1982; Rubin \& Wenzel, 1996; Rubin et al., 1986) the retention function for recent years has been found to be a power function; that is, a straight line on logarithmic scales. We excluded memories less than 1-day old because the dating procedure did a poor job of distinguishing these memories from one another. The remaining period of 3,652 days between 1 day and 10 years was divided into 10 equal steps on a logarithmic scale, each step being approximately twice as long as the one more recent than it. The number of memories falling within each step was calculated for each group as a whole. It should be noted that on the logarithmic scale, the most recent year is more important than the preceding 9 years; the ratio of 1 year to 1 day is $365: 1$, whereas the ratio of 10 years to 1 year is $10: 1$. Because the differential encoding hypothesis would not predict much change within a year, the power function fit is viewed as a measure of retention and not as a measure of age-dependent differential encoding.

Fits were made with the power function expressed as $\ln (y)$ $=-m \cdot \ln (t)+b$. For the 20,20b, 35, 70,73, and 73b groups, the slopes (with standard errors) were $-.97(.02),-.69(.03)$, $-1.07(.03),-1.03(.02),-.93(.03)$, and $-.90(.03)$, respec- tively. All squared correlation values were greater than .99 except for the $20 \mathrm{~b}$ group, which had an $r^{2}=.98$. These values agree with earlier work in that the power function provides a good fit to the data. Thus, a two-parameter function, which was chosen because it fit earlier data sets, accounted for $99 \%$ of the variance. Given the lack of experimental control, this is noteworthy. Both the correlations and the slopes are consistent with those found by Rubin et al. (1986) for 15 different data sets, fitting mostly within the earlier -.83 to -1.07 range.

Five of the data sets have slopes between .90 and 1.07 , which are close to each other; the .69 slope of the $20 \mathrm{~b}$ is somewhat of an outlier. Thus, the bias instructions for the $20 \mathrm{~b}$ group, but not for the $73 \mathrm{~b}$ group, had a major impact on slope. This appears to be because the bias toward early memories appears to have extended into the second decade of life, which includes the most recent 10 years of life for the $20 \mathrm{~b}$ group.

\section{The Distribution of Word-Cued Memories Over the Earliest Decade}

A component is needed that goes to zero at some age between 0 and 3 . This component must be different from the retention function, which is based on time ago rather than on age (i.e., time from birth ). Figure 1 plots the average number of memories per participant at each of the first 10 years of life. All groups were combined because there were too few memories to plot groups separately on a year-by-year basis. The curve in this and all figures was fit by eye (or computer program) to make the trends clearer visually rather than to fit and test equations. Table 2 contains the number of memories before age 3 and before age 10 for the individual groups. As expected, there are few memories before age 3 .

As can be noted in Table 2, the 35-year-old group has fewer memories before age 10 than any other group. This low number of memories in the first decade of life is noteworthy because the 35-year-old group has half as many years to distribute their memories in as the older groups, and so under one reasonable

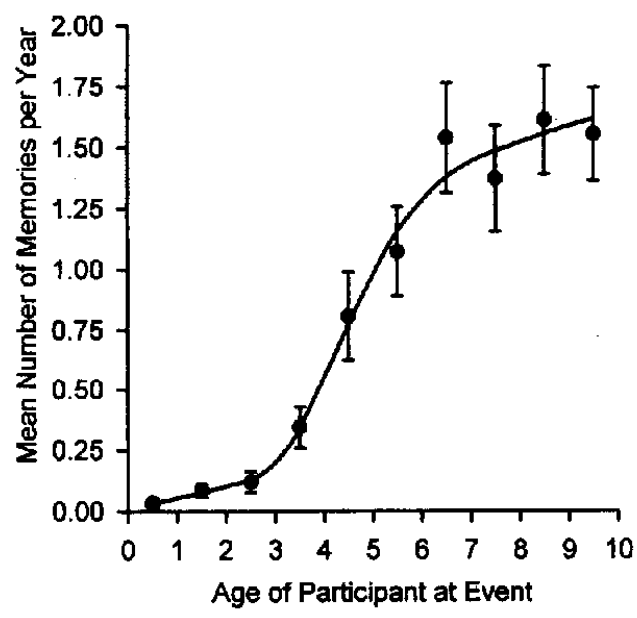

Figure 1. Distribution of the word-cued autobiographical memories for all participants in the six groups was combined for the first 10 years of their lives. Error bars are $\pm 1 S E$. 
null hypothesis they should have twice as many memories in their earliest decade. As can also be seen in Table 2, the bias instructions produced about twice as many memories in this period as the standard instructions. A 2 (standard vs. biased instructions $) \times 2$ (20- vs. 73-year-old group) analysis of variance (ANOVA) produced an effect of instructions, $F(1,74)=$ 9.63, $M S E=129.61$, but not of the age of the group, $F(1,74)$ $=2.79, M S E=129.61, p=.10$, or of their interaction, $F(1$, 74) $=0.56, M S E=129.61, p=.46$. As can be seen in Table 2 , there were few memories before age 3 , and so the effect must be on memories from the 3- to 9-year-old period.

Thus the standard childhood amnesia component is replicated, and the bias instructions are shown to have their expected effects on early memories. The $\mathbf{3 5}$ group, both for its most recent and earliest memories, shows a tendency to focus on recent, as opposed to early, events.

\section{The Distribution of Word-Cued Memories Over the Life Span}

Figure $2 \mathrm{~A}$ contains the data from the 70,73 , and $73 \mathrm{~b}$ groups that came from each of the seven decades of participants' lives. The 60-to-69 decade contains more than 10 years, extending beyond 69 into these participants 70 th or 73 rd year. The three plots of Figure $2 \mathrm{~A}$ are similar, with the biasing instructions producing a tendency toward more early memories. As shown in Figure $2 \mathrm{~A}$ and Table 2, there are also fewer recent memories in the biased group. If the average logarithm of the age of the memories from each participant in the $20,20 \mathrm{~b}, 73$, and $73 \mathrm{~b}$ groups is examined, the bias groups produce older memories, $F(1,76)=12.73, M S E=0.44$, the older groups produce older memories, $F(1,76)=29.27, M S E=0.44$, and there is no interaction, $F(1,76)=2.69, M S E=0.44, p=.10$. The geometric mean age of memories for the $20,20 \mathrm{~b}, 73$, and $73 \mathrm{~b}$ groups were $86,502,939$, and 1,807 days, respectively. The distribution of the age of memories was highly skewed, as indicated in the power function fit and as shown in Table 2; thus the logarithms and geometric means were used to avoid having the presence or absence of a few old memories swamp differences among the more recent memories.

Two analyses argue for the reliability of the bump. The first is the remarkable agreement between this and the earlier studies. The values obtained here for the 70,73 , and $73 \mathrm{~b}$ groups were predicted by the past values from Rubin et al. (1986, Figure 12.2 ) in a simple regression analysis with $r^{2}$ s of $.988, .973$, and .537 , and the average absolute magnitudes of the residuals were $0.5 \%, 0.9 \%$, and $3.5 \%$. Thus, there is a reasonable fit for all groups and an excellent fit for the two groups that did not have the biased instructions. As can be seen from the magnitude of the individual differences among participants in Experiment 2 of Rubin and Schulkind (in press) and from the standard errors in Figure 2A, such a high degree of correspondence might not be obtained on replication. Second, on the basis of Rubin et al. (1986) and other studies reviewed in the introduction, the bump was defined as an increase in memories from between 10 and 30 compared with surrounding periods. We contrasted the percentage of memories in the 10- to 29-year period with those from the two following decades, using a 2 ( 10 to 29 vs. 30 to $49) \times 3$ ( 70 vs. 73 vs. 73 b) ANOVA that resulted in a significant
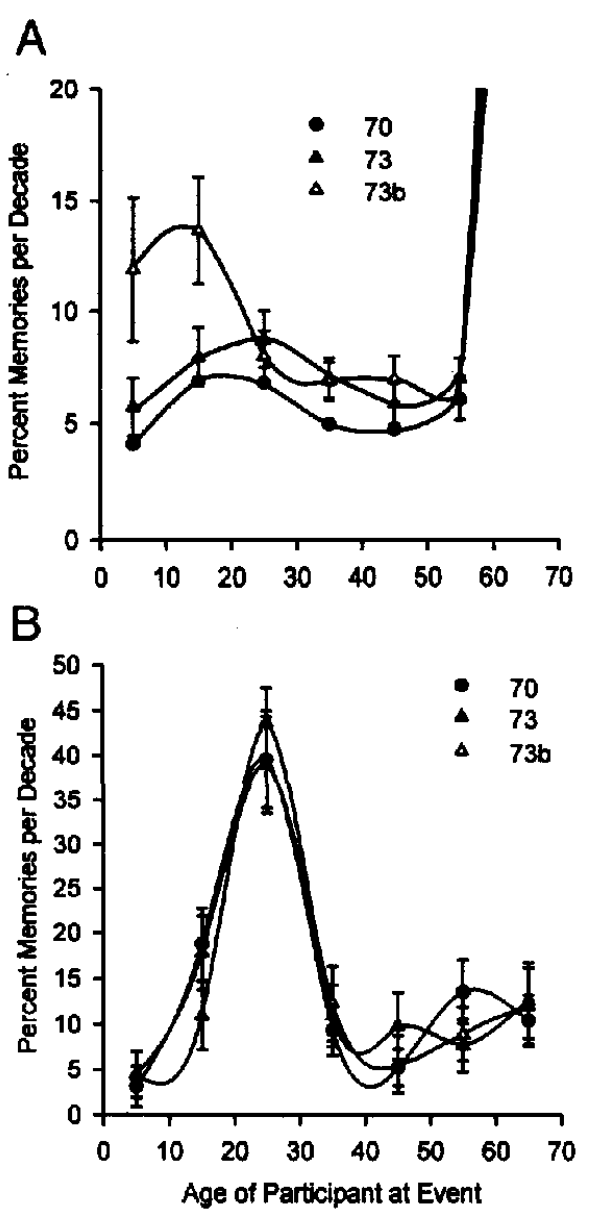

Figure 2. (A) The distribution of the word-cued autobiographical memories from the 70,73 , and $73 \mathrm{~b}$ groups. The values for the most recent interval do not fall within the figure because they have means (and standard errors) of $65.50 \%(6.14 \%), 57.54 \%(5.86 \%)$, and $46.45 \%$ (6.26\%), respectively. (B) The distribution of each group member's five important memories. Error bars are $\pm 1 S E$. b indicates biased instructions.

effect of the bump, $F(1,57)=9.42, M S E=230.10$, but not of the group, $F(2,57)=0.01, M S E=419.98$, or of their interaction, $F(2,57)=0.24, M S E=230.10$. Contrasting the 10to-29 period to the two surrounding decades produced similar results: decade effect, $F(1,57)=13.36, M S E=102.00$; group effect, $F(2,57)=0.33, M S E=714.34$; and interaction, $F(2$, 57) $=0.79, M S E=102.00$.

Jansari and Parkin (1996) have argued for the use of 5-year bins instead of decades to get a clearer picture of the bump. When 5-year bins are used instead of decades, the bump appears broader and flatter, nearly uniform from 5 to 34 . The bias condition, like Jansari and Parkin's data, has a peak in the 5-to-9 range and fewer memories after age 25 . Given the general lack of memories in the 0 -to- 3 range and the moderate number of memories in the first decade of life, it is likely that in earlier work, as well as in the data collected here, the bump would need to be extended back to age 5 or so; that is, back to the childhood amnesia component. Whether the bump should be 
extended from age 30 to 35 remains an open question, which awaits further data.

The distribution of the 35 group is shown in Figure $3 \mathrm{~A}$ in which 5-year periods were used instead of decades. The 35 group shows a hint of leveling in the 20 -to- 24 period, but we do not have anywhere near enough power to determine whether the differences of this size represent the start of the bump or just a random fluctuation in the data. A decrease following the bump would also have been hard to detect because it might have been swamped by recent memories. That is, the problem may be the lack of a trough that is needed to define the nonmonotonic bump, a problem amplified because the 35 group, as indicated by its steeper slope on the retention function fit to recent memories and its relative lack of early memories, focused on the present more than any other group. Why the participants in the 35 group focused on their most recent past remains a topic for further investigation.
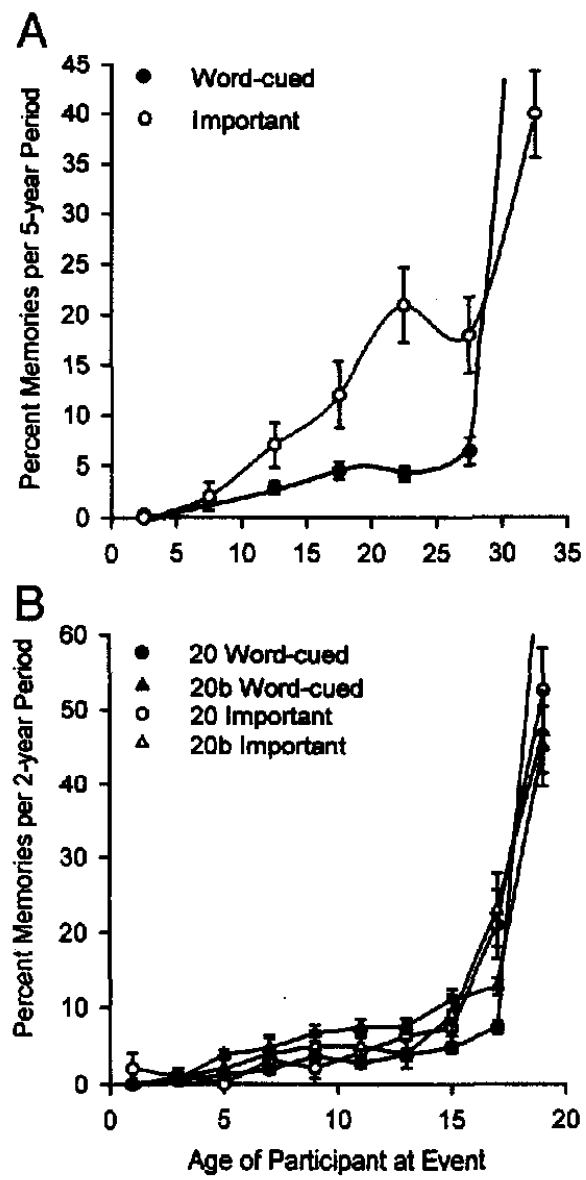

Figure 3. (A) The distribution of the word-cued and the five important autobiographical memories for the 35 group. The value for the most recent interval for the word-cued memory does not fall within the figure because it has a mean (and standard error) of $79.98 \%(4.05 \%$ ). (B) The same distributions for the 20 and $20 \mathrm{~b}$ groups. The value for the most recent interval for the word-cued memory 20 group does not fall within the figure because it has a mean (and standard error) of $73.82 \%$ $(4.48 \%)$. Error bars are $\pm 1 S E . \mathrm{b}$ indicates biased instructions.
In summary, the bump appears clearly for the 70 and 73 groups but not for the $\mathbf{3 5}$ group. For the older groups, an analysis in 5-year, as opposed to 10-year, periods yielded a flatter and broader distribution.

\section{Reaction Times to Produce Word-Cued Memories}

Initial analyses were performed using the arithmetic mean and the geometric mean (i.e., with the logarithms of the reaction times). As there were minimal differences, throughout the article we use the simpler arithmetic mean for reaction times. As is expected from the general literature on aging (Cerella, 1985; Salthouse, 1991, 1994), as well as from studies of autobiographical memory (Fitzgerald \& Lawrence, 1984; Holding et al., 1986), reaction time slowed with age. For the 20, 20b, 35, 70, 73 , and $73 \mathrm{~b}$ groups the average time in seconds (and standard deviation) to retrieve a memory was $9.55(3.40), 13.62(8.69)$, $16.73(12.39), 16.61(7.33), 21.05$ (11.89), and $17.87(13.30)$, respectively. A one-way ANOVA yielded an overall effect of group, $F(5,114)=3.02, M S E=102.08$. A 2 (standard vs. biased instructions $) \times 2(20$ - vs. 73 -year-old group $)$ ANOVA yielded an overall effect of group, $F(1,76)=12.25, M S E=$ 92.06, but not of instructions, $F(1,76)=2.60, M S E=92.06$, $p=.11$, or of their interaction, $F(1,76)=0.04, M S E=92.06$.

The distribution of reaction times over decades was examined. Jansari and Parkin's (1996) participants had faster reaction times when asked for memories from the period from birth to 20-years-old than when asked for the period from 10 to 20 years ago; however, the faster reaction times were from the period that was twice as long and more clearly delimited by landmarks. Here participants were asked to produce memories from anywhere in their lives, and no clear differences in reaction time appeared. For the 20, 20b, and 35 groups, we used 5-year intervals instead of decades because their data were distributed over a shorter period. There were significant differences in reaction times for four of the six groups. For three groups this was due to the earliest period being either slower (20 and 70 ) or faster $(20 \mathrm{~b})$ than the other periods. For the $73 \mathrm{~b}$ group, the 40 to- 49 decade was slower than the remaining decades. There was no obvious pattern to these results, but the youngest period was the one with the fewest memories on which to calculate an average reaction time for each participant. When this earliest period was removed from the $20,20 \mathrm{~b}$, and 70 groups and the 40-to-49 decade was removed from the $73 b$ group, no group had a significant effect. This mix of results is not satisfying, but at least the 10-to-29 period of the bump is not responsible for the differences in reaction time, and so differences in reaction time cannot account for the bump.

\section{Analyses of Cue Word Effects}

The 124 cue words were selected because they had been previously normed on 51 properties including measures of autobiographical memory (Rubin, 1980). Data were therefore averaged over participants to provide values for each of the 124 cue words used. In this way the data collected here could be analyzed using standard properties of words. Because the values for each age group intercorrelated about as highly as their reliabilities, measures were made for the combined 20,35 , and $70 /$ 
73 age groups. The reaction time measure and the geometricmean-days-ago measure for these three age groups were reliable, with Cronbach's alphas in the $.45-.91$ range. The reaction time measures correlated among themselves in the $.45-.57$ range, and the days-ago measures correlated in the $.41-.50$ range. Reaction time measures correlated negatively with the days ago measures, in the $.02--.51$ range, indicating that there is a tendency for words that cue older memories to cue with faster retrievals. In general, imageable, concrete, and meaningful words cued autobiographical memories more often and faster and cued older autobiographical memories. This is in agreement with Fitzgerald and Lawrence (1984) who rated their cue words on imagery and meaningfulness and found similar correlations. The relationship of concreteness and imagery with reaction time was caused in part by abstract words causing especially long retrievals.

A main concern of this article is how memories from various periods of the life span differ. To aid in this analysis we formed four more dependent measures for each cue word from the 70,73 , and 73 b groups combined by calculating the proportion of the memories that each word produced that fell in childhood $(0-9$ years $)$, the bump $(10-29)$, middle years $(30-49)$, and older years $(50-69)$. The proportion of memories from 0 to 9 and the proportion of memories from 30 to 49 were predicted with $r$ s between .28 and .33 by imagery and concreteness. The proportion in the bump was predicted with $r$ s of .18 and .22 , respectively. This finding is consistent with concrete, sensory concepts predicting earlier memories (Rubin, 1982; Rubin et al., 1984) and with the correlations obtained here between imagery and concreteness and the geometric-mean-days-ago measure. However, there are no special properties of words likely to cue memories in the bump. For more details see Rubin and Schulkind (1997). Thus, the analysis of the properties of the word cues used to evoke memories presented a reasonable picture with consistent results across groups. However, it does not help us to understand why the bump occurred.

\section{The Distribution of Important Memories Over the Life Span}

The distribution of the memories selected by the participants as being their five most important should provide a possible way to account for the bump. The 20 and 20 b groups' distributions of important memories are shown in Figure 3B in which 2-year bins along with their distribution of word-cued memories for comparison were used. Both plots were converted to percentage of total memories to allow comparison on the same scale. These participants are in the middle of their bump period and so should be encoding memories that will be differentially recalled when they are older. For the 20 and $20 \mathrm{~b}$ group, there are few important memories until 17 and 18 with a sharp peak in their 19th and 20 th years. For most participants, these were the years containing their transition from high school to college, and transitions are known to lead to important memories (Pillemer, Picariello, Law, \& Reichman, 1996). However, a simpler explanation for the 20 and $20 \mathrm{~b}$ groups is that important and cued memories have indistinguishable distributions, both of which can be described as retention functions.
Figure $3 \mathrm{~A}$ contains the distribution of the important as well as the word-cued memories for the $\mathbf{3 5}$ group. Important memories follow the same general pattern as the cued memories, but because $80 \%$ of the memories come from the most recent 5-year period, the rest of the word-cued-memory curve is suppressed. Like the 20 and $20 \mathrm{~b}$ groups, the plots of the 35 group show a nearly monotonic increase in important memories with age. The curve, which is drawn through all of the points, has a local peak between ages 20 and 24, but, as can be seen from the standard error bars, a monotonic curve also fits within the confidence interval of the points. The important memories shown in Figure 3A differ from plots in Fitzgerald (1996), which show a clear bump with a drop in the number of memories after age 25 for both vivid memories and memories that the participants chose for books about their lives. Here, there is only a hint of such a bump. Although the median age of the participants in Fitzgerald's study was 36 and thus nearly equal to our 35-year-old participants, his range of ages was much larger, from 31 to 46. Thus, Fitzgerald's older participants may have contributed to the difference. Another possibility could be differences in the level of education. With older participants, the distribution of vivid memories seems to peak later for more educated participants.

The older participants' distribution of important memories is shown in Figure 2B, their distribution of word-cued memories is shown in Figure $2 \mathrm{~A}$. As with the 20 and $20 \mathrm{~b}$ groups, the bias versus standard instructions, which had its intended effect on word-cued memories, did not affect the selection of important memories. Also like the 20 and $20 \mathrm{~b}$ groups, the important memories are concentrated in the bump; for the older participants, the important memories are mainly in the 20 -to- 29 decade. Because the three groups are so similar, they could be combined and plotted in 5-year intervals. If this is done, the sharp peak in the 20-to-29 decade remains. The location of this peak is different from Fromholt and Larsen's (1991, 1992; Fromholt, Larsen, \& Larsen, 1995) peak for important memories in the 10-to-19 decade or Fitzgerald's (1988) distribution of vivid memories for 70 -year-olds, which peaks at 16 to 20 . As with the 20 and $20 \mathrm{~b}$ groups, the 70,73 , and $73 \mathrm{~b}$ groups showed very good agreement, and so the differences between this and earlier studies are unlikely to be a random fluctuation. Rather, the move toward higher ages for the peak follows the years of education of these three groups $(7,12$, and 16 years, respectively). This is consistent with the idea that as years of education increase, the age at which normatively important events, such as marriage, changing from schooling to work, and changing job status, is delayed.

The 70 and 73 groups showed a striking difference between their distribution of word-cued and important memories with important memories concentrated much more in the bump in the single 20 -to- 29 decade. The 20 and 35 groups did not show this clear distinction between word-cued and important memories, though the 35 group shows a hint of a bump between ages 20 and 24 . Overall, the $20,20 \mathrm{~b}$, and 35 groups viewed their recent lives as producing more important events than any other period, whereas the 70,73 , and $73 \mathrm{~b}$ groups did not.

\section{Ratings of Selected and Important Memories}

After the 124 cue words were given, 12 to 14 memories were selected from among those cued to produce a uniform 
distribution of memories over the life span, and each of these memories as well as the important memories was rated on five 7 -point rating scales (vividness, pleasantness, significance, novelty, and frequency of rehearsal) and on one 3-point scale (memory-perspective), which produced no clear results. In addition, emotionality was calculated as the absolute value of the pleasantness rating minus four, the neutral value on the scale. The scales appear to have some validity. For the 30 possible combinations of the six groups with the five scales that one would assume to have higher ratings for the important memories than for the word-cued memories (i.e., vividness, significance, novelty, frequency of rehearsal, and emotionality), important memories were rated statistically more highly than word-cued memories in 30 out of 30 cases. In all but 5 of those 30 cases, an $F$ test with 1,19 degrees of freedom was significant at the .0001 level. However, no clear pattern emerged across decades for the word-cued memories, and so these rating scale responses do not help us understand the bump except to again say that bump memories do not differ from those from other periods.

In particular, data from each of the seven rating scales were analyzed in separate 3 (group: 70 vs. 73 vs. $73 \mathrm{~b}$ ) $\times 7$ (decade) ANOVAs. Five of the rating scales - rehearsal, novelty, vividness, emotionality, and pleasantness - showed a significant effect of decade. However, memories from the bump decades (10-to-19 and 20-to-29) were not rated consistently higher than memories from other periods. For example, memories from the 10-to-19 decade received the seventh, fifth, sixth, sixth, and fifth highest mean ratings in terms of rehearsal, novelty, vividness, emotionality, and pleasantness, respectively. Memories from the 20-to-29 decade received the first, fourth, fourth, and third highest mean ratings. This is not clear evidence for an increase in the bump. More directly, when comparing the 20-year bump period (10-to-29) to the 20-year postbump period (30-to-49), none of the 2 (period) $\times 3$ (group) ANOVAs had a significant effect of period. Further, similar analyses comparing just the 20 to-29 decade (i.e., the decade that produced a peak for the five most important events) to the 30 -to-49 postbump period also showed no effect of the bump. This is in spite of the power afforded by analyzing the responses of all 57 participants who answered the ratings scales.

One unexpected finding, however, is worth mention; for many scales the older groups had higher ratings than the younger groups for either the word-cued or the important memories. For the word-cued memories, the rating scales of vividness, significance, frequency of rehearsal, and emotionality from the 70,73 , and $73 \mathrm{~b}$ groups all had ratings of higher magnitude than did the $20,20 \mathrm{~b}$, and 35 groups. For the important memories this was true for the rating scales of vividness and pleasantness. For these six scales, ANOVAs ( $d f \mathrm{~s}=1,119$ ) between the scores of the younger (i.e., the $20,20 \mathrm{~b}$, and 35 groups combined) and older (i.e., the 70,73 , and $73 \mathrm{~b}$ groups combined) groups were all significant at the .0001 level, except for word-cued significance that was significant at the .005 level. The only other significant $F$ was word-cued pleasantness $(p<.05)$. As this is an unexpected, post hoc finding, not much can be made of it except that it warrants further study.

\section{Discussion}

What do we know about the distribution of autobiographical memories over the life span? What periods of life produce auto- biographical memories when people are cued with words and are asked to recall events'? Replicating published work, we found that people of a range of ages have few memories from before their third birthday. This necessitates the inclusion of a function in which the shape is dependent on the age of the participant rather than on how long ago the memory occurred. Also replicating published work, we found that people of a range of ages can have the distribution of memories from the most recent 10 years of their lives described well by a power function with a slope that does not vary systematically with age. Because the power function provides a good fit for retention of laboratory material, we consider this aspect of autobiographical memory as a retention function. With just the power function or with the power function plus the childhood amnesia function, people who are 70-years-old would recall very few memories from before age 30 . This, however, is not the case. In addition to these two components, there must be something that causes memories from ages 10 to 30 (i.e., from the bump) to be recalled better.

The distribution of memories did prove to be malleable with changes in instructions that biased people to recall either recent or old memories. The three components remained, but changed in the direction that was expected given the instructions. Biasing toward older memories produced more childhood memories and less recent memories, but the functions themselves seemed to keep the same general forms.

One unexpected finding is that for older, but not for younger, adults, the distribution of important and word-cued memories differed. When 70- and 73-year-old adults were asked to provide memories important in their lives, they did not give many recent events, whereas younger adults did. This effect may have more to do with external changes over the life span and how our culture interprets them than with memory, but the bump emerged clearly only in those groups for which the distribution of wordcued and important memories differed; that is, for those groups for which their most important memories were in their more remote past.

Examining our other dependent measures, we found an increase in reaction time with age but no systematic change in reaction time for memories retrieved from different parts of the life span. Rating scale measures such as vividness, importance, significance, emotionality, frequency of rehearsal, and novelty also did not vary in systematic ways over the life span, though memories reported by the participants as being their most important did differ in reasonable ways from the word-cued memories on these scales. An interesting unexpected finding was that the older adults rated their memories, especially their word-cued memories, as higher on many scales. The properties of the cue words produced reliable measures that interrelated in reasonable ways and that were somewhat successful in predicting which words would produce older memories. However, they did not predict which words would produce memories in the bump.

Thus, after a careful search in which many of the standard techniques of cognitive psychology were brought to bear, we are left with a set of quantitative, repeatable findings - findings that either held for all six groups or varied systematically with the different ages and instructions of the groups. Moreover, the techniques we used were able to address many possible explana- 
tions for the bump. In particular, consider the seven hypotheses about the bump, six of which proposed a separate mechanism for the bump.

The first hypothesis was that demand characteristics produced the bump, with participants trying to produce more bump memories implicitly or explicitly to follow expectations set up by the experiment. This can be rejected because biasing instructions that tried to mimic demand characteristics that would produce the bump had a relatively small effect in the 10-to-30 period compared with size of the bump, mostly affecting the first decade of life. There may be some set of instructions that would have dramatic effects on the bump for word-cued memories, such as "Please report only memories from between the ages of 10 and 30.' However, it is unlikely, given our results, that any instructions or biases transmitted by experimenters in the published literature would have had a major effect on the existence of the bump, though they could certainly cause more memories from the earlier years of the bump. The second hypothesis was the related claim that the bump exists because people spend more time on retrieving memories from the 10 -to- 30 period, thereby tolerating longer searches for memories in that period. The reaction time data did not support this claim. Thus, two explanations that border on artifacts can be rejected.

The third hypothesis was that the bump was caused by the large number of especially important memories from the 10to-30 period, which provided highly available memories for recall and provided a possible set of memories that could be used to prompt related memories. Two forms of data from older adults argued against this hypothesis. The first was that the word-cued memories from the bump were not judged as more important or significant than memories from other time periods. The second was that the distribution of important memories and the distribution of word-cued memories differed too much. A core of especially important memories could account for the 20-to-30 portion of the bump in our data but not for the 10-to-20 portion. In the literature on the distribution of important and vivid memories, different studies produce different distributions of memories. The claim here is that if both unrestricted and important memories were sampled from the same participants, the two distributions would differ in the bump period. Thus, important memories can offer, at best, a partial explanation of the bump or perhaps a full explanation of part of the bump.

The fourth hypothesis was that the bump was caused by the disproportionate inclusion of bump memories within the central narrative of one's life. This hypothesis was not supported because memories from the bump were not rated as being more significant nor were they rated as being told more often. The fifth hypothesis was that bump memories were for more novel or distinctive events, events that would have received more processing and less proactive interference. This hypothesis was not supported because memories from the bump were not rated as being more novel. The sixth hypothesis was that bump memories were more vivid or emotional and thus were preserved better. This hypothesis was not supported because memories from the bump were not rated as being more emotional or vivid. When a less direct test was used, this hypothesis was also not supported because emotional or concrete cue words did not have differential effects.

This does not mean that Hypotheses 3, 4, 5, and 6, which are based on life narrative or memories that are generally more important, vivid, emotional, or novel, must be rejected. It is possible that these theories could work in a less direct way. For instance, under the narrative theory, there could be more rehearsal of memories from the bump leading to more of them being recalled, but there still might not be an increase in the number of retellings among these recalled memories when compared with memories from outside the bump. Consider an oversimplified version of the narrative theory that claims that only memories told 10 times will be recalled after 1 year. According to this theory, there will be more memories recalled from the bump period because these menories are part of the life narrative and are told more than 10 times. However, among all the memories that are recalled, there is no reason to claim that memories from the bump will be retold more often. That is, the values for the rating scales reported here are conditional on the memories being recalled.

Nonetheless, from examining the first six hypotheses it appears that memories in the bump seem just like memories from other periods of life, there are just more of them. Thus, the seventh hypothesis should be considered, even though it was never tested directly. It remains possible that memories from the bump are encoded in a way that makes them easier to retrieve later in life other than by the other factors considered here. Direct support for this hypothesis was not presented here. Nonetheless, if conditions present at retrieval have minimal effect on the bump, and if the memories recalled from within the bump do not differ from other memories, then researchers must begin to consider other explanations.

\section{References}

Anderson, J. R., \& Schooler, L. J. ( 1991). Reflections of the environment in memory. Psychological Science, 2, 396-408. New York: Freeman. Baddeley, A. D. (1992). What is autobiographical memory? In M. A. Conway, D. C. Rubin, H. Spinnler, \& W. A. Wagenaar (Eds.), Theoretical perspectives on autobiographical memory (pp. 13-29). Dordrecht, the Netherlands: Kluwer Academic.

Benson, K. A., Jarvi, S. D., Arai, Y., Thielbar, P. R. S., Frye, K. J., \& McDonald, B. L. G. (1992). Socio-historical context and autobiographical memories: Variations in the reminiscence phenomenon. In M. A. Conway, D. C. Rubin, H. Spinnler, \& W. Wagenaar (Eds.), Theoretical perspectives on autobiographical memory ( $\mathrm{pp}$. 313322). Dordrecht, the Netherlands: Kluwer Academic.

Brewer, W. F. (1996). What is recollective memory? In D. C. Rubin (Ed.), Remembering our past: Studies in autobiographical memory (pp. 19-66). Cambridge, England: Cambridge University Press.

Cerella, J. (1985). Information processing rates in the elderly. PsychoLogical Bulletin, 98, 67-83.

Cohen, G., Conway, M. A., \& Maylor E. A. (1994). Flashbulb memories in older adults. Psychology and Aging, 9, 454-463.

Cohen, G., \& Faulkner, D. (1988) . Life span changes in autobiographical memory. In M. M. Gruenberg, P. E. Morris, \& R. N. Sykes (Eds.) Practical aspects of memory: Current research and issues: Vol. 1 . Memory in everyday life ( $p$ p. 277-282). New York: Wiley.

Conway, M. A. (1990). Autobiographical memory: An introduction. Milton Keynes, England: Open University Press. 
Conway, M. A., \& Rubin, D. C. (1993). The structure of autobiographical memory. In A. E. Collins, S. E. Gathercole, M. A. Conway, \& P. E. Morris (Eds.), Theories of memory (pp. 103-137). Hove, England: Erlbaum.

Conway, M. A., Rubin, D. C., Spinnler, H., \& Wagenaar, W. A. (Eds.). (1992). Theoretical perspectives on autobiographical memory. Dordrecht, the Netherlands: Kluwer Academic.

Crovitz, H. F., \& Schiffman, H. (1974). Frequency of episadic memories as a function of their age. Bulletin of the Psychonomic Society, 4, $517-518$

Crovitz, H. F., Schiffman, H, \& Apter, A. (1991). Galton's number Bulletin of the Psychonomic Society, 29. 331-332.

Fitzgerald, J. M. (1988). Vivid memories and the reminiscence phenomenon: The role of a self narrative. Human Development, 31, 261273.

Fitzgerald, J. M. (1996). Intersecting meanings of reminiscence in adult development and aging. In D. C. Rubin (Ed.), Remembering our past: Studies in autobiographical memory (pp. 360-383). Cambridge, England: Cambridge University Press.

Fitzgerald, J. M., \& Lawrence, R. (1984). Autobiographical memory across the life-span. Joumal of Gerontology, 39, 692-699.

Franklin, H. C., \& Holding, D. H. (1977). Personal memories at different ages. Quarterly Journal of Experimental Psychology, 29, 527532.

Fromholt, P., Larsen, P., \& Larsen, S. F. (1995). Effects of late-onset depression and recovery on autobiographical memory. Joumal of Gerontology: Psychological Sciences, 50, 74-81.

Fromholt, P., \& Larsen, S. F. (1991). Autobiographical memory in normal aging and primary degenerative dementia (dementia of the Alzheimer type ). Journal of Gerontology: Psychological Sciences, 46, 8591.

Fromholt, P., \& Larsen, S. F. (1992). Autobiographical memory and lifehistory narratives in aging and dementia (Alzheimer type). In M. A. Conway, D. C. Rubin, H. Spinnler, \& W. Wagenaar (Eds.), Theoretical perspectives on autobiographical memory (pp. 413-426). Dordrecht, the Netherlands: Kluwer Academic.

Galton, F. (1879). Psychometric experiments. Brain, 2, 149-162.

Gergen, K. J., \& Gergen, M. M. (1983). Narratives of the self. In T. R. Sarbin \& K. E. Scheibe (Eds.), Studies in social identity (pp. 254273). New York: Praeger.

Giambra, L. M., \& Arenberg, D. (1993). Adult age differences in forgetting sentences. Psychology and Aging, 8, 451-462.

Holding, D. H., Noonan, T. K., Pfau, H. D., \& Holding, C. S. (1986). Date attribution, age, and the distribution of lifetime memories. Journal of Gerontology, 41, 481-485.

Howes, J. L., \& Katz, A. N. ( 1992). Remote memory: Recalling autobiographical and public events across the lifespan. Canadian Joumal of Psychology, 46, 92-116.

Huttenlocher. J., Hedges, L., \& Prohaska, V. (1988). Hierarchical organization in ordered domains: Estimating the dates of events. Psychological Review, 95, 471-484.

Hyland, D. T., \& Ackerman, A. M. (1988). Reminiscence and autobiographical memory in the study of the personal past. Journal of Gerontology: Psychological Sciences, 43, 35-39.

Jansari, A., \& Parkin, A. J. (1996). Things that go bump in your life: Explaining the reminiscence bump in autobiographical memory. Psychology and Aging, $11,85-91$.

Larsen, S. F., Thompson, C. P., \& Hansen, T. (1996). Time in autobiographical memory. In D. C. Rubin (Ed.), Remembering our past: Studies in autobiographical memory (pp. 129-156). Cambridge, England: Cambridge University Press.

Neisser, U. (1988). Commentary on "Vivid memories and the reminiscence phenomenon: The role of a self narrative." Human Development, 31, 271-273.
Neisser, U., \& Fivush, R. (1994). The remembering self: Construction and accuracy of life narrative. Cambridge, England: Cambridge University Press.

Nigro, G., \& Neisser, U. (1983). Point of view in personal memories. Cognitive Psychology, 15, 467-482.

Pillemer, D. B., Picariello, M. L., Law, A. B., \& Reichman, J. S. (1996). Memories of college: The importance of specific educational episodes. In D. C. Rubin (Ed.), Remembering our past: Studies in autobiographical memory (pp. 318-337). Cambridge, England: Cambridge University Press.

Rabbitt, P., \& Winthorpe, C. (1988). What do old people remember? The Galton paradigm reconsidered. In M. M. Gruenberg, P. E. Morris, \& R. N. Sykes (Eds.), Practical aspects of memory: Current research and issues: Vol. 1. Memory in everyday life (pp. 301-307). New York: Wiley.

Robinson, J. A. (1992). First experience memories: Contexts and function in personal histories. In M. A. Conway, D. C. Rubin, H. Spinnler, \& W. Wagenaar (Eds.), Theoretical perspectives on autobiographical memory (pp. 223-239). Dordrecht, the Netherlands: Kluwer Academic.

Robinson, J. A. (1996). Perspective, meaning, and remembering. In D. C. Rubin (Ed.), Remembering our past: Studies in autobiographical memory (pp. 199-217). Cambridge, England: Cambridge University Press

Robinson, J. A., \& Swanson, K. L. (1993). Field and observer modes of remembering. Memory, $l, 169-184$.

Rubin, D. C. (1980). 51 properties of 125 words: A unit analysis of verbal behavior. Journal of Verbal Learning and Verbal Behavior, 19 $736-755$.

Rubin, D. C. (1982). On the retention function for autobiographical memory. Journal of Verbal Learning and Verbal Behavior, 21, 2138.

Rubin, D. C. (Ed.). (1986). Autobiographical memory. Cambridge, England: Cambridge University Press.

Rubin, D. C. (Ed.). (1996). Remembering our past: Studies in autobiographical memory. Cambridge, England: Cambridge University Press.

Rubin, D. C., \& Baddeley, A. D. (1989). Telescoping is not time compression: A model of dating autobiographical events. Memory \& Cog nition, 17, 653-661.

Rubin, D. C., Groth, L., \& Goldsmith, D. (1984). Olfactory cuing of autobiographical memory. American Journal of Psychology, 97, 493507.

Rubin, D. C., Rahhal, T. A., \& Poon, L. W. (in press). Things learned in early adulthood are remembered best: Effects of a major transition on memory. Memory \& Cognition.

Rubin, D. C., \& Schulkind, M. D. (1997). Properties of word cues for autobiographical memory. Psychological Reports, 81, 47-50.

Rubin, D. C., \& Schulkind, M. D. (in press). The distribution of autobiographical memories across the lifespan. Memory \& Cognition.

Rubin, D. C., \& Wenzel, A. E. (1996). One hundred years of forgetting: A quantitative description of retention. Psychological Review, 103, $734-760$

Rubin, D. C., Wetzler, S. E., \& Nebes, R. D. (1986). Autobiographical memory across the adult lifespan. In D. C. Rubin (Ed.), Autobiographical memory (pp. 202-221). Cambridge, England: Cambridge University Press.

Salthouse, T. A. (1991). Mediation of adult age differences in cognition by reductions in working memory and speed of processing: Psychological Science, 2, 179-183.

Salthouse, T. A. (1994). Aging associations: Influence of speed on adult age differences in associative learning. Journal of Experimental Psychology: Learning, Memory, and Cognition, 20, 1486-1503. 
Tulving, E. (1972). Episodic and semantic memory. In E. Tulving \& W. Donaldson (Eds.), Organization of memory (pp. 382-403). New York: Academic Press.

Webster, J. D., \& Cappeliez, P. (1993). Reminiscence and autobiographical memory: Complementary contexts for cognitive aging research. Developmental Review, 13, 54-91.

Wickelgren, W. A. (1975). Age and storage dynamics in continuous recognition memory. Developmental Psychology, 11, 165-169.
Wixted, J. T., \& Ebbesen, E. B. (1991). On the form of forgetting. Psychological Science, 2, 409-415.

Received October 31, 1996

Revision received January 23, 1997

Accepted January 23, 1997

\title{
Call for Nominations
}

The Publications and Communications Board has opened nominations for the editorships of Experimental and Clinical Psychopharmacology, Journal of Experimental Psychology: Human Perception and Performance (JEP:HPP), Journal of Counseling Psychology, and Clinician's Research Digest for the years 2000-2005. Charles R. Schuster, PhD, Thomas H. Carr, PhD, Clara E. Hill, $\mathrm{PhD}$, and Douglas $\mathrm{K}$. Snyder, $\mathrm{PhD}$, respectively, are the incumbent editors.

Candidates should be members of APA and should be available to start receiving manuscripts in early 1999 to prepare for issues published in 2000 . Please note that the P\&C Board encourages participation by members of underrepresented groups in the publication process and would particularly welcome such nominees. Self-nominations are also encouraged.

To nominate candidates, prepare a statement of one page or less in support of each candidate and send to

Joe L. Martinez, Jr., PhD, for Experimental and Clinical Psychopharmacology

Lyle E. Bourne, Jr., PhD, for JEP:HPP

David L. Rosenhan, PhD, for Journal of Counseling Psychology

Richard M. Suinn, PhD, for Clinician's Research Digest

Send all nominations to the appropriate search committee at the following address:

\author{
Karen Sellman, P\&C Board Search Liaison \\ Room 2004 \\ American Psychological Association \\ 750 First Street, NE \\ Washington, DC 20002-4242
}

First review of nominations will begin December 8, 1997. 